\title{
The donation system of bodies for use in medical education in Sweden
}

\author{
Gunnar Grant \\ Department of Neuroscience, Karolinska Institutet, Stockbolm, Sweden
}

\begin{abstract}
In 1964 the World Health Organization (WHO) arranged a workshop in Uppsala, Sweden, to study new ways and methods of improving the teaching of anatomy. An important matter of discussion was a donation system of bodies for use in anatomical dissection. The report from the workshop was prepared by the Regional Office for Europe and distributed to the governments of member states in the region. It included information on donation systems from countries where these had been used and was placed at the disposal of other interested countries. In Sweden this meant the introduction of an accepted system for receiving bodies for anatomical dissection and the abolition in 1973 of an old order to different public institutions to supply bodies for dissection. That was out of date in a modern society and did not function properly. Since the introduction of the donation system in Sweden, every single specimen for anatomical dissection derives exclusively from donations by free will of people who have decided in their lifetime to donate themselves, for the benefit of medical education. The Christian religion, which is still dominating in Sweden, although the country has become successively more secularized, creates no hindrance for donations. Special forms are used. One copy is kept by the donator, another by the department. The donated bodies are embalmed using an alcohol-glycerol-phenol solution, without formaldehyde. The supply of donated bodies allows specialists from our hospitals to carry out surgical interventions on the donated bodies, for the benefit of their training.
\end{abstract}

Key words: body donation system; teaching of anatomy; Sweden

Anatomy 2008; 2: 16-21, (C) 2008 TSACA

\section{The new System for Acquiring Bodies for Anatomical Dissection Introduced in Sweden in the Mid 1960s}

In 1964 the World Health Organization (WHO) arranged a workshop in Uppsala, Sweden, to study new ways and methods of improving the teaching of anatomy (Figure 1). There were participants from several European countries, from the United States and from the Soviet Union (Table 1). An important matter of discussion was a donation system of bodies for use in anatomical dissection. The report from the workshop, from which I acted as rapporteur, was prepared by the Regional Office for Europe, in Copenhagen, and distributed to the governments of member states in the region and to the participants in the working group. It included information on donation systems from countries where these had been used and was placed at the disposal of other interested countries. In Sweden, this meant the introduction of an accepted system for receiving bodies for anatomical dissection and the abolition in 1973 of an old order to different public institutions to supply bodies for dissection. Before, the bodies of people who died for instance at mental hospitals without relatives asking for them, were supposed to be sent to the nearest anatomical department for use in dissection for teaching purposes. I still remember that the professor of anatomy in Uppsala, my scientific supervisor, Bror Rexed, who later became head of the Swedish Board for Health and 
Welfare and finally worked for WHO, told me how very uneasy he felt about the system and did not like calling the head of the local mental hospital to remind him of his duty to send bodies of deceased people to our anatomy department. The system did not work well. There was a constant lack of bodies for the teaching of medical students at the anatomy departments in our country. In addition, the system was definitely out of date in a modern society. It was Bror Rexed who initiated the workshop in 1964, already then having had contacts with WHO. ${ }^{1}$

\section{All Bodies for Anatomical Dissection Are Now Donated by Free Will}

The Christian religion, which is still dominating in Sweden, although the country has successively become more secularized, creates no hindrance for donations.

Since the introduction of the donation system in our country, every single specimen for anatomical dissection derives exclusively from donations by free will of people who have decided in their lifetime to donate their bodies, to the benefit of medical education.

\section{WORKING GROUP TO STUDY NEW WAYS AND METHODS OF IMPROVINO THE TEACHING OF ANATOMY}

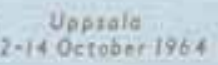

REGIONAL OFFICE FOR EUROPE

World Health Organizasion COPENHAGEN
Figure 1. Front cover of Report from Working Group convened by the Regional Office for Europe of the World Health Organization, 1964. 
In translation from Swedish, our donation form at Karolinska Institutet in Stockholm looks like this:

(PAGE 1)

Karolinska Institutet

Department of

17177 Stockholm

Phone:
Registration number.

(Copy for the division of anatomy)

\section{Donation Form}

I hereby declare it as my definite will that my body after my death shall be placed at the disposal for the aid of anatomical teaching and research at the Department of Neuroscience, Karolinska Institutet, which also includes the teaching division of anatomy.

In this connection I wish that my body or some organ/organs are donated to the division of anatomy for all future time:

YES NO

Special requirements in case of donation of organs

I have discussed my donation with my closest family members/next of kin, namely....

They have declared that they will not oppose the completion of this donation

In regards to my wishes in connection with the donation, I wish to provide the following information:

Name:

National registration number:.

Address:

Profession/title

Marital status:

Married

Unmarried

Divorced

Widow/Widower

We hereby certify that.

being in sound mind, and by his/her own free will and in agreement with her/his closest family members/next of kin has signed the declaration above

1. Name:.

Address:

2. Name:

Address:

On behalf of the teaching division of anatomy, this donation is gratefully received:

Stockholm ..... / $20 \ldots$ 
(PAGE 2)

I wish funeral service - Christian burial $\quad$ Yes No

funeral service - civil burial $\quad$ Yes No

cremation (not applicable if the body has been donated to the division of anatomy for all future time) Yes $\quad$ No interment in an urn grave $\quad$ Yes No

$\begin{array}{ll}\text { interment of the ashes in a memorial grove } & \text { Yes No }\end{array}$

a) The funeral service:.

b) The interment (if this is desired).

c) Place for the interment (in an urn grave, of ashes in a memorial grove)

NOTE! In some cases (see the information form) the reception of the body may have to be declined, and in such a case the costs for the burial will not be covered by Karolinska Institutet. In such a case (yes/no), I permit another anatomical division in the country to accept this donation.

I want to cover the costs for the funeral myself

Possible funeral expenses fund, funeral insurance or similar, to be put at the disposal of the division of anatomy

Name:.

Membership number:

In good time before the interment (in an urn grave, of the ashes in a memorial grove) the following persons shall be informed:

1. Name:.

Name:.

3. Name:

Date :
Address:

Phone:.

Address:

Phone:.

Address:

Phone:

Signature: 
One copy of the form is kept by the division of anatomy. The other is sent back to the donator together with a card to be kept e.g. in the wallet or purse.

Karolinska Institutet pays for transport, coffin, organist, priest and interment in urn grave.

\section{Embalming Procedure without Formaldehyde}

Once the body has been embalmed by the division of anatomy, the body is kept for up to 6-7 months. This does naturally not apply for donations which have been made for all future time, but those are extremely few.

After the embalming the bodies are normally kept in a refrigerator, at a temperature of about +4 degrees centigrade. Only occasionally are they placed in an alcohol bath.

The embalming solution was changed several years ago in order to avoid the negative effects of the traditional formalin. Formalin is now not used at all. The solution is composed of alcohol (95\%; 6 l), glycerol (1 1), phenol $(5 \% ; 2.51)$ and water (4 l). Injections are made into the carotid arteries, one vessel at a time $(0.51$ upwards and 3-4 1 downwards) and into the femoral arteries, also one vessel at a time (a few liters downwards and somewhat less of the remainder of the 13.5 liters upwards). With this procedure the tissue is well preserved and the joints still flexible, which was not the case with the previous approach. The procedure has eliminated the unpleasant and unhealthy smell that characterized the earlier embalming method with formaldehyde containing solutions. The smell of phenol is not a problem and was found in a test to be 1/20000 of the allowable level. Altogether this has meant that the atmosphere in the dissection theatre for students and personnel has improved dramatically.

\section{Adequate Supply of Bodies for Anatomical Dissection also Benefits Clinicians}

We receive 20-25 bodies per year in Stockholm. Fourteen of these are used for the two annual courses for medical students, each with 130-140 students. Dental students also carry out dissections of neck and face. Some bodies are transferred to Uppsala and Linköping, where there are fewer donations.

Table 1

List of participants in the Working Group.

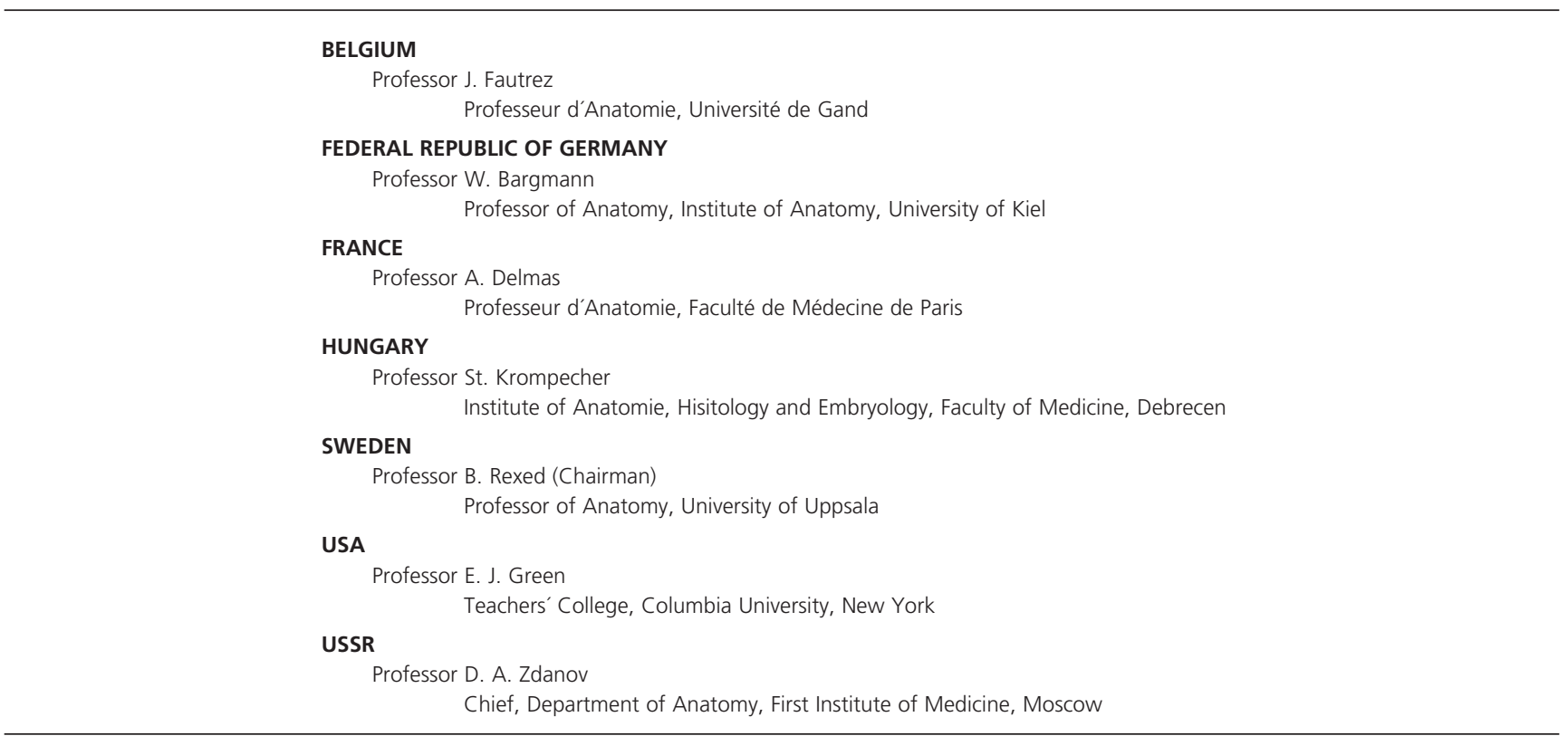


The supply of bodies also means that we can offer specialists from our hospitals to carry out surgical interventions on the donated bodies. This can not be done at pathology units any more, as it used to be, with the rules that we now have in Sweden. Furthermore, postmortem examinations, which were earlier carried out in about $90 \%$ of all cases of death in our country, have been reduced to about $5 \%$. We have had courses in our division of anatomy at Karolinska Institutet with orthopedic surgeons carrying out shoulder surgery, ear-nose and throat-specialists sinus surgery, neurosurgeons specialized brain surgery, and plastic surgeons and dental sur- geons making use of the donated bodies for the benefit of their training. The donation system has thus become of great importance, not only for the preclinical teaching, but also for the training of specialists in the medical field. The new system is a great success and works extremely well.

\section{Reference}

1. Report on a Working Group convened by the Regional Office for Europe of the World Health Organization. Uppsala 12-14 October 1964. New ways and methods of improving the teaching of anatomy. Distributed by the Regional Office for Europe. World Health Organization: Copenhagen; 1965.

Correspondence to: Professor emeritus Gunnar Grant Department of Neuroscience, Karolinska Institutet, Retzius väg 8, B2:5, SE-171 77 Stockholm, Sweden. e-mail: e-mail address: gunnar.grant@ki.se

Conflict of interest statement: No conflicts declared. 